\title{
Magnitude eleitoral e representação de mulheres nos municípios brasileiros
}

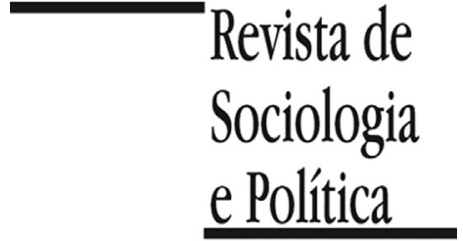

DOI 10.1590/1678-987317256304

\author{
Fernando Meireles e Luciana Vieira Rubim Andrade
}

\begin{abstract}
Resumo
É argumento corrente na literatura sobre representação política de mulheres que sistemas mais proporcionais aumentam as chances de mulheres serem eleitas. O objetivo deste artigo é testar esta hipótese usando dados dos municípios brasileiros. Explorando uma regra estabelecida pelo Tribunal Superior Eleitoral em 2004 e 2008, que fixou o número de vereadores de cada município de acordo com o número de habitantes, utilizamos regressão descontínua (RD) para estimar o efeito causal de uma cadeira a mais na representação política de mulheres nas câmaras municipais. Nossos resultados mostram que este efeito é substantivo: onde havia uma cadeira adicional, quase $40 \%$ mais mulheres foram eleitas, e a probabilidade de um município eleger ao menos uma mulher aumentou em cerca de 20 pontos percentuais. Por outro lado, a explicação deste fenômeno contraria as hipóteses da literatura: especificamente, mostramos que uma cadeira a mais aumentou apenas o número de candidatos homens concorrendo, o que fragmentou suas votações e os deixou com desempenhos eleitorais piores. Deste modo, mesmo não tendo suas votações afetadas pelo número de cadeiras, mais mulheres acabaram eleitas.
\end{abstract}

PALAVRAS-CHAVE: representação política de mulheres; estudos de gênero; magnitude eleitoral; municípios brasileiros; câmara de vereadores.

Recebido em 11 de Fevereiro de 2016. Aceito em 28 de Setembro de 2016.

\section{Introduçãa ${ }^{1}$}

\author{
${ }^{1}$ Agradecemos aos \\ comentários a versões \\ anteriores, apresentadas no \\ Programa de Pós-Graduação \\ em Ciência Política da \\ Universidade Federal de \\ Minas Gerais. Agradecemos \\ também aos pareceristas \\ anônimos da Revista \\ Sociologia e Política.
}

$\mathrm{H}$ á tempos a presença de mulheres na política institucional é pequena. Mulheres não só ocupam menos cargos institucionais, mas também eletivos, e isso mesmo em democracias consolidadas (Reynolds 1999; Norris 2006; Schwindt-Bayer 2010; Roberts, Seawright \& Cyr 2012; Sacchet 2013). Inevitavelmente, isto impõe problemas à democracia. O fato de que espaços legislativos sejam ocupados majoritariamente por homens significa, entre outras coisas, que a perspectiva das mulheres, determinada por suas posições sociais e experiências de vida, pode não ser devidamente representada (Young 2006). A inclusão de diferentes perspectivas na arena de representação formal poderia gerar resultados positivos para os processos decisórios que envolvam a elaboração e implementação de políticas públicas, por exemplo (Matos \& Ramalho 2010; Young 2006). Na medida em que mulheres, bem como outros grupos minoritários, estejam sub-representados no poder Legislativo, o sistema político deixa de incorporar ou incorpora de forma insuficiente questões fundamentais, tornando-se menos inclusivo.

Tratados e conferências internacionais já abordaram este problema a partir de diferentes enfoques. A Plataforma de Ação de Beijing, de 1995, por exemplo, conclamou aos países signatários a se comprometerem com a inclusão de mulheres na política, incentivando a transversalização da temática de gênero em diferentes instâncias políticas (Viotti 2006). Como uma das possíveis respostas, no Brasil foi sancionada a Lei Federal 9.100, de 1995, que estabeleceu que ao menos 20\% das vagas das listas partidárias nas eleições municipais de 1996 deveriam ser preenchidas por mulheres - número posteriormente fixado para um mínimo 30\% de candidaturas de cada sexo, a partir de 1997, e estendido 
${ }^{2}$ Um exemplo é a campanha "Mais mulheres no Poder - Eu assumo esse Compromisso", lançada em 2008. A campanha é fruto da parceria entre o Fórum Nacional de Instâncias de Mulheres dos Partidos Políticos, o Conselho Nacional de Direitos da Mulher, a Procuradoria Especial da Mulher do Senado Federal, a Bancada Feminina da Câmara dos Deputados e a Procuradoria da Mulher da Câmara dos Deputados (Brasil 2014, p.2).

\footnotetext{
${ }^{3}$ Os dados utilizados para calcular estas estatísticas foram retirados do Repositório de Dados Eleitorais do Tribunal Superior Eleitoral (TSE). Na Seção III.2 e no Apêndice 1, descrevemos em detalhes os dados utilizados no artigo.
}

para pleitos legislativos estaduais e federais. No entanto, a adesão à Lei foi baixa, visto que a legislação não previa sanções aos partidos que a descumprissem. Apenas em 2009 um mínimo orçamentário (5\%) do Fundo Partidário e do total da propaganda partidária e eleitoral (10\%) foi destinado à participação de mulheres, bem como previsão de sanção aos partidos que não a cumprissem (Rezende 2015). Também no Brasil, com a elevação da Secretaria de Política para as Mulheres ao status ministerial, vimos surgir diversas campanhas ${ }^{2}$ e conferências nacionais de política para as mulheres. Essas iniciativas forneceram importantes subsídios para a construção dos Planos Nacionais de Política para as Mulheres. No segundo deles há a inclusão de um eixo específico sobre a participação de mulheres na política (Brasil 2008, p.121).

Apesar destes e outros esforços, o número de mulheres ocupando cargos eletivos no Brasil ainda é baixo. Em 2015, o país ocupava apenas o $156^{\circ}$ lugar no ranking da União Interparlamentar sobre a participação de mulheres nos parlamentos (Brasil está na lanterna... 2015). Especificamente, a Câmara dos Deputados nunca teve mais de $10 \%$ de mulheres eleitas num pleito desde a redemocratização. Nos municípios, o número de prefeitas também nunca passou de $11 \%$ do total e, no caso das câmaras municipais, apenas $12 \%$ dos vereadores são mulheres, em média. Mesmo a Lei de Cotas ainda hoje não é cumprida em diversos lugares: nas eleições de 2012, em 261 municípios o número mínimo de $30 \%$ de candidaturas de mulheres ao cargo de vereadora não foi atingido; como era de se esperar, em média $13 \%$ de vereadoras foram eleitas nestes municípios - 67 destes não elegeu nenhuma mulher ${ }^{3}$. Mesmo assim, existem variações importantes no número de mulheres eleitas neste nível local e, de acordo com a literatura, parte dela poderia ser explicada por alguns fatores institucionais (Araújo 2009; Sacchet 2013).

Estudos comparados mostram que o principal fator que explicaria o número de mulheres ocupando cargos eletivos seria o tipo de sistema eleitoral. Sistemas proporcionais, onde candidatos competem por mais de uma vaga sob listas partidárias, tenderiam a produzir resultados eleitorais mais representativos do que sistemas majoritários, onde normalmente apenas o candidato mais bem votado se elege. De fato, uma série de estudos mostra que países com arranjos proporcionais têm, em média, mais mulheres nos legislativos (Reynolds 1999; Norris 2006; Salmond 2006; Schwindt-Bayer 2010). Contudo, como argumenta Engstrom (1987), variações institucionais podem acontecer num mesmo país, já que é perfeitamente possível existirem distritos com diferente número de cadeiras no mesmo momento. Como sugerem alguns autores, inclusive, este seria o principal aspecto do sistema proporcional que impactaria o sucesso das mulheres candidatas (Engstrom 1987; Matland 1993; Norris 2006, p.201).

Com mais cadeiras em disputa, a competição eleitoral diminui, isto é, menos votos relativos são necessários para se eleger. Ao contrário, onde existem uma ou poucas vagas em jogo, os próprios líderes partidários poderiam vetar candidaturas de mulheres para promover a de homens, normalmente considerados mais competitivos (Valdini 2013, p.78). Além disso, caso um partido selecione mulheres para competir, os demais partidos também podem ser compelidos a fazer o mesmo para evitar que se forme a percepção de que candidaturas de mulheres estão sendo preteridas (Araújo 2005, p.196; Engstrom 1987; Matland 1993). Deste modo, portanto, maior magnitude eleitoral promoveria mais candidaturas de mulheres, bem como aumentaria as chances de elas conseguirem se eleger.

Neste artigo, procuramos testar esta hipótese. Especificamente, nosso objetivo é examinar se o número de cadeiras em disputa realmente tem um efeito causal sobre a representação de mulheres, tomando as câmaras municipais brasileiras como objeto de análise. Para fazer isto, contudo, um problema 
empírico maior precisa ser superado: o de endogeneidade. Municípios com diferentes números de cadeiras também podem ser sistematicamente diferentes em outros aspectos, tanto observáveis (tamanho da população, número de partidos etc.) quanto não-observáveis (p.ex., machismo da população). Em segundo lugar, geralmente são os próprios legisladores que decidem quantas cadeiras estarão em disputa com base em razões estratégicas (Boix 1999; Renwick 2010). Na presença destes dois problemas não temos como saber se a diferença no número de vereadoras entre municípios com número de cadeiras diferentes se deve somente a isso. Assim, precisamos de outra abordagem.

A abordagem utilizada é quase-experimental: a regressão descontínua (RD). Especificamente, exploramos uma resolução do Tribunal Superior Eleitoral (TSE) para as eleições de 2004 e 2008 que fixou o número de cadeiras para as câmaras municipais de acordo com faixas populacionais: municípios com até um número pré-estabelecido de habitantes tiveram um determinado número de cadeiras; ao contrário, municípios com pelo menos um habitante a mais do que este patamar pré-estabelecido ganharam uma cadeira adicional (Cepaluni \& Mignozzetti 2015; Corbi, Papaioannou \& Surico 2014). Assim como em pesquisas experimentais, a ideia aqui é nos aproveitar do fato de que o tratamento (ter uma cadeira a mais) foi distribuído de forma exógena aos municípios com populações próximas destes patamares estabelecidos pelo Tribunal Superior Eleitoral (TSE) - o que nos permite justamente compará-los como se fossem grupos de tratamento e de controle, sem nos preocuparmos com a influência de outras covariáveis (Imbens \& Lemieux 2008).

Conforme discutimos na Seção III, este desenho também é útil por razões mais substantivas. A participação das mulheres no governo local, por exemplo, é a que tem menor custos para elas. Adicionalmente, o cargo de vereador é muitas vezes a porta de entrada para outras carreiras na política (Bohn 2009; Miguel 2003), além de oferecer a oportunidade de atuação no âmbito local, onde a implementação e fiscalização de diversas políticas públicas importantes acontece e o contato com os eleitores é mais direto (Brollo \& Troiano 2016; Matos \& Ramalho 2010). Além das implicações normativas, portanto, o estudo do efeito da magnitude eleitoral sobre a representação de mulheres nas câmaras municipais nos dá importantes insights sobre a inserção de mulheres na política local, algo ainda pouco estudado no Brasil (Araújo 2009; Matos \& Ramalho 2010, p.44).

Nossos resultados mostram que, de fato, a magnitude eleitoral tem impacto considerável sobre a representação de mulheres: como documentamos na Seção IV, uma cadeira adicional causa em média um aumento de cerca de 0,45 no número de vereadoras eleitas - perto da metade do que os municípios analisados aqui elegem em média, que é de 1,16. Além disso, a probabilidade de um município com uma cadeira a mais eleger ao menos uma mulher vereadora aumenta em cerca de 20 pontos percentuais, o que mostra que o efeito da magnitude é ainda maior nos locais em que a eleição de mulheres é mais difícil. Ainda que estes efeitos pareçam pequenos de forma absoluta, eles são substantivos, significando que uma pequena mudança institucional como esta pode realmente contribuir para reduzir a sub-representação de mulheres.

Também mostramos que nenhum dos mecanismos causais mobilizados pela literatura supracitada para explicar o efeito da magnitude eleitoral encontra suporte empírico neste contexto. Na verdade, um outro mecanismo, ainda não considerado, é que parece explicar o aumento do número de vereadoras: a fragmentação da competição eleitoral no campo dos candidatos homens. Analisando uma série de variáveis intermediárias, mostramos que o número de candidatas mulheres e a votação delas não aumenta com uma cadeira adicional, o que indica que o efeito da magnitude eleitoral não incentiva mais mulheres a 
se candidatar, nem mais eleitores a votarem nelas. Por outro lado, uma cadeira adicional causa um aumento expressivo no número de candidatos homens, o que, por seu turno, fragmenta a votação de todos eles e os deixa menos competitivos vis-à-vis candidatas mulheres - que mantêm seus desempenhos constantes independentemente do número de cadeiras disponíveis. Por estas e outras evidências discutidas na Seção IV.1, sustentamos que se trata de um problema de coordenação entre candidatos homens, e não outros mecanismos, que explica como uma cadeira a mais aumenta o número de mulheres eleitas nos municípios analisados. Na conclusão, retomamos a discussão destes resultados e de suas implicações, tanto para a literatura quanto para o debate público sobre a participação política de mulheres.

\section{Representação política de mulheres e magnitude eleitoral}

\section{II.1. Representação política de mulheres nos municípios brasileiros}

\footnotetext{
${ }^{4}$ Uma das vias de atuação política dos movimentos feministas e de mulheres foi a entrada para o Estado, com secretarias, organismos institucionais de mulheres, candidaturas para todos os cargos eletivos, participação em conselhos, enfim, todas as arenas institucionais e estatais. Esta é, para Matos (2010), uma das características da "quarta onda" dos movimentos feministas latino-americanos.

${ }^{5}$ Os movimentos feministas e de mulheres também se posicionaram de forma a alcançar maior inclusão de mulheres na política institucional, além do que já está previsto legalmente. Entre as propostas levantadas pelos movimentos, observa-se consenso em manter a representação proporcional e em implementar a lista fechada com alternância de sexo (Rezende \& Assis 2014, p.126).
}

Desde a conquista dos direitos políticos, os movimentos de mulheres e feministas estiveram presentes em momentos importantes da política brasileira. Participaram, por exemplo, da luta pela redemocratização; no período da constituinte, se aproximaram e se inseriram em instituições políticas e, finalmente, entraram no Estado de forma robusta ${ }^{4}$ (Matos 2010; Pinto 2003). No entanto, Sacchet (2013) afirma que o sistema eleitoral brasileiro não favorece essa participação. Isto decorreria do sistema proporcional de lista aberta, que faz com que a disputa seja intrapartidária e com altos custos financeiros para os candidatos $^{5}$. Neste contexto, mulheres seriam geralmente prejudicadas, pois elas comumente arrecadam e investem menos dinheiro em suas campanhas (Miguel \& Biroli 2010, p.668-669; Sacchet \& Speck 2012; Sacchet 2013, p.100).

Em eleições municipais, estes custos da participação de mulheres, mesmo que significativos, são mais baixos (Bohn 2009). Nestas disputas, mulheres não precisam viajar constantemente, podendo permanecer próximas de suas famílias, dos seus locais de trabalho, bem como em outras atividades que exercem - já que muitas vezes mulheres possuem duplas ou triplas jornadas de trabalho (Matos \& Ramalho 2010, pp.43-44). Além disso, a participação das mulheres em lideranças comunitárias, de igrejas, entre outras, poderia minimizar os custos financeiros com a campanha, já que isto lhes forneceriam bases eleitorais sólidas.

Por outro lado, a participação política de mulheres nos municípios também pode ser benéfica por motivos mais substantivos. Para Massolo (2005), mulheres eleitas para cargos municipais têm o potencial de atuar efetivamente em políticas capazes de melhorar a vida de famílias e comunidades. De acordo com o argumento, mulheres participam mais em tarefas relacionadas às necessidades básicas das famílias e comunidades; tratam mais de temas sociais, como a pobreza, e também em assuntos "tipicamente" femininos, como educação e saúde. Brollo e Troiano (2015) encontram suporte para esta última afirmação, mostrando que mulheres prefeitas atraem mais investimentos federais para a saúde e melhoram serviços de atendimento pré-natal em seus municípios, o que, por sua vez, reduz o número de bebês nascidos prematuros. Desta forma, a participação local de mulheres pode influenciar políticas que visam atender demandas urgentes de mulheres e crianças e, também, a implementação focada de políticas nacionais, como é o caso de muitas das políticas voltadas para mulheres ou demais políticas sociais que beneficiam principalmente as mulheres - caso do Programa Bolsa Família.

Apesar da importância do tema, poucos estudos tratam da representação de mulheres na política local brasileira. Ao analisar as arrecadações de campanhas em municípios de tamanhos diferentes, Sacchet (2013) afirma que, quanto 
maior o município, mais recursos os candidatos a vereador precisam arrecadar para suas campanhas, tornando-se mais difícil a inserção de mulheres nas câmaras, já que elas arrecadariam menos recursos, tanto financeiros quanto tempo no horário eleitoral. Já Miguel e Queiroz (2006) mostram que em regiões menos desenvolvidas do Brasil, como Norte, Nordeste e Centro-Oeste, as mulheres têm melhor desempenho eleitoral do que em outras regiões. Particularmente, este resultado contraria a hipótese de que existe correspondência entre desenvolvimento econômico e maior participação de mulheres.

Como também mostra esta literatura, a participação política de mulheres nos municípios brasileiros é mínima. Embora a percentagem de prefeituras comandadas por mulheres venha crescendo nos últimos anos - passou de $5 \%$, em 2000, para 7\%, em 2004, 9\%, em 2008, e 11\%, em 2012 - no caso das câmaras, o número médio de vereadoras eleitas por município pouco mudou, tendo passado de 11\%, em 2000, para pouco mais de $13 \%$ em 2012. Nesta última eleição, cerca de 33\% das câmaras não elegeu mulheres. Nas eleições de 2008 e 2004, este número é ainda maior: $36 \%$ e $38 \%$, respectivamente. O mais saliente, entretanto, é a que baixa representação de mulheres, apesar de algumas exceções, é o padrão no Brasil todo: o Gráfico 1 mostra isto espacialmente, por meio de um mapa temático. O mapa também sugere que a explicação para a variação no número de mulheres eleitas parece não residir em fatores regionais/espaciais - o que deixa algum espaço para a análise de pequenas variações no sistema eleitoral, como na magnitude eleitoral.

\section{II.2. O efeito da magnitude eleitoral na representação de mulheres}

O argumento majoritário, na literatura, sobre o efeito da magnitude eleitoral na representação de mulheres é bastante simples: quanto maior é a magnitude,

Gráfico 1 - Proporção de vereadores eleitos por sexo nas eleições municipais de 2012

Proporção de vereadoras eleitas

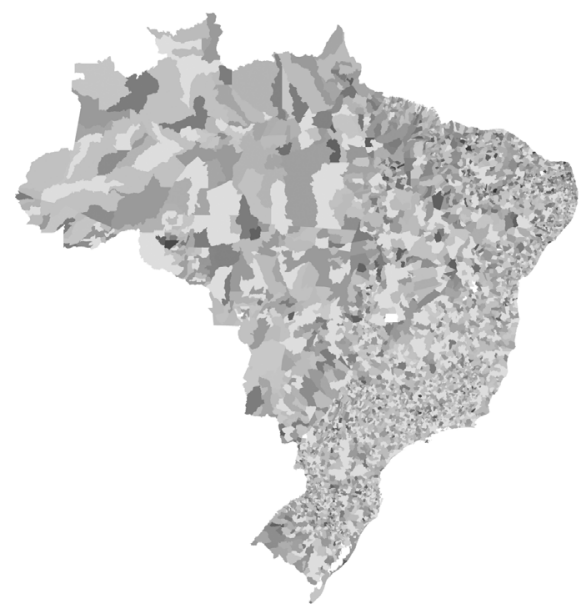

Proporção

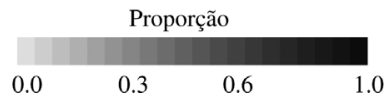

Proporção de vereadores eleitos
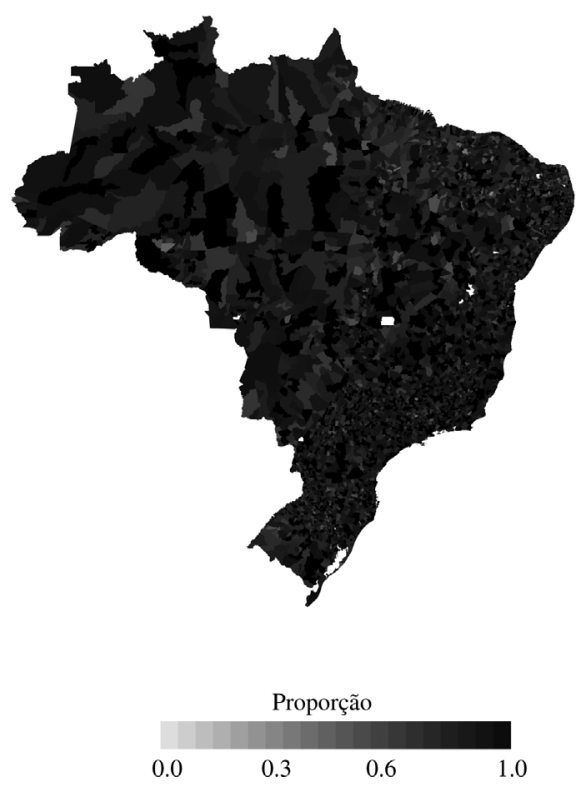

Fonte: Os autores, a partir das fontes descritas no Apêndice.

Nota: O mapa mostra a proporção de vereadores eleitos por sexo (número de vereadores eleitos de determinado sexo / total de vereadores eleitos) nas eleições de 2012. O valor 0, representado por cinza claro, indica que nenhum vereador com o sexo mencionado foi eleito num dado município; o valor 1, representado em preto, indica que todas as cadeiras foram ocupadas por vereadores do sexo mencionado. Cores intermediárias indicam valores intermediários na escala. 
${ }^{6}$ Para boas revisões teóricas sobre os efeitos da magnitude eleitoral na representação de mulheres, ver Matland (1993) e Engstrom (1987); para uma revisão sobre os efeitos de vários sistemas eleitorais na representação de mulheres, ver Norris (2006), Reynolds (1999) e Schmidt (2009) mais mulheres são eleitas (Engstrom 1987; Matland 1993; Miguel \& Queiroz 2006, p.365; Norris 2006, p.201; Schwindt-Bayer 2010, p. 46). Particularmente, esta afirmação encontra suporte em vários estudos, que mobilizam principalmente três mecanismos para sustentar esta proposição ${ }^{6}$ : primeiro, que sistemas proporcionais alocariam cadeiras de forma mais proporcional entre candidatos; segundo, que eles incentivariam mais candidaturas de mulheres; terceiro, que eles incentivariam eleitores a votar de forma não-estratégica.

O primeiro mecanismo atuaria na fase de tradução de votos em cadeiras. Em sistemas majoritários, especialmente onde apenas um candidato se elege por distrito, normalmente os eleitos não obtêm a maioria dos votos válidos. Por causa disso, os votos de segundos e terceiros candidatos - os menos competitivos - acabam não sendo aproveitados na composição dos legislativos; como muitos candidatos que representam grupos politicamente minoritários frequentemente não conseguem grande volume de votos, isto significa que, na prática, eles acabam sendo sub-representados (Norris 2006; Reynolds 1999). Esta distorção entre votos e eleitos, embora varie de acordo com diversas características, seria menor em sistemas com maior magnitude eleitoral, onde justamente mais cadeiras são alocadas por distrito e, por consequência, candidatos menos competitivos têm maiores chances de se eleger (Reynolds 1999, p.555; Schwindt-Bayer 2010, p.46). Em outras palavras, a consequência básica de mais cadeiras em disputa seria a de aumentar a representação de mulheres relativamente a sistemas com baixa magnitude.

Maior magnitude eleitoral também poderia aumentar a representação de mulheres por meio da seleção de candidatos. Tipicamente, líderes partidários têm incentivos para recrutar candidatos com maior potencial de votos nas eleições. O que uma série de estudos mostra, contudo, é que tanto na perspectiva dos líderes quanto na das candidatas as mulheres seriam menos competitivas e, por isso, acabariam não sendo recrutadas (Araújo 2005, p.195; Dowling \& Miller 2015, p.56). Maior magnitude diminuiria estes incentivos: com mais vagas a serem preenchidas, há mais espaço para que minorias tenham candidaturas sem que, com isso, outros grupos percam espaço (Engstrom 1987; Matland 1993; Schmidt 2009). Do mesmo modo, tudo o mais mantendo-se constante, o risco de não eleger candidatos diminui, já que o número de votos necessários para se eleger também cai - especialmente em sistemas de lista, onde os votos de todos os candidatos ajudam o partido a ganhar mais cadeiras (Schmidt 2009, p.191). Portanto, de acordo com este argumento, maior magnitude eleitoral promoveria mais candidaturas femininas e isto, por sua vez, poderia aumentar o número de mulheres eleitas.

Por último, a literatura sugere que o efeito da magnitude eleitoral atuaria não apenas pelo lado da oferta, por meio do aumento e do sucesso no número de candidatas, mas também pelo lado da demanda. De acordo com este argumento, poucas cadeiras em jogo incentivariam um tipo de comportamento utilitarista nos eleitores que seria prejudicial às candidatas: eleitores não votariam em mulheres por temerem "desperdiçar" seus votos, ou, em outras palavras, eles poderiam deixar de votar numa candidata preferida, mas com menos chances de ser eleita, para votar em um candidato menos preferido, mas com mais chances de ser eleito (Matland 1993, p.739; Valdini 2013, pp.78-80). Este comportamento estratégico poderia tirar votos que iriam para mulheres, caso no próprio eleitorado exista a percepção de que mulheres têm menores chances de se eleger vis-à-vis candidatos homens. Deste modo, quanto maior for a magnitude eleitoral, menor seria o incentivo de os eleitores votarem desta forma estratégica e, consequentemente, melhor seria o desempenho das candidatas mulheres.

Segundo estas hipóteses, poderíamos esperar que mais cadeiras aumentariam a representação de mulheres. De todo o modo, alguns fatores podem intervir 
neste efeito. O tipo de lista eleitoral, fechada ou aberta, afeta a forma como as campanhas são feitas. Neste sistema, usado nas eleições para as câmaras municipais brasileiras, a disputa acontece dentro das listas, isto é, os melhores colocados dentro delas são eleitos para as cadeiras obtidas pela lista como um todo. Como sustentam vários estudos (Miguel \& Queiroz 2006, p.365; Schmidt 2009; Valdini 2013, p.77), isto gera incentivos para a personalização das campanhas e acirramento das disputas dentro dos partidos, seja na captação de recursos, seja na obtenção de apoio das máquinas partidárias e de eleitores. Neste caso, candidatas mulheres poderiam ser prejudicadas, já que candidatos homens tenderiam a ser privilegiados por doadores, líderes partidários e eleitores.

Outra das possíveis explicações para a variação no efeito da magnitude, que pode anular aquela relação esperada pela literatura, como argumenta Matland (1993, p.742), seria o número de partidos existentes no sistema partidário: onde existem muitos partidos, líderes partidários poderiam apoiar poucas candidaturas, preferencialmente de homens, já que eles teriam a expectativa de obter poucas cadeiras. Também não é difícil aventar a hipótese de que coligações pré-eleitorais podem agir no mesmo sentido, impedindo que líderes partidários montassem listas de forma equilibrada - desde que cada partido indicasse seus candidatos independentemente uns dos outros, ou seja, de forma não coordenada. Ainda que estes argumentos não sejam consensuais na literatura (Schmidt 2009; Valdini 2013), o ponto é que existem razões plausíveis para se acreditar que o sistema partidário possa barrar a inserção de mulheres na política institucional - mesmo que ocorram mudanças nas regras eleitorais.

Em resumo, o que estes últimos estudos sugerem é que o efeito da magnitude eleitoral pode não ser algo automático, como sugere a maioria da literatura: dependendo do contexto em que opera, ele pode produzir resultados distintos. Estudando casos de reforma eleitoral comparativamente, por exemplo, Roberts, Seawright e Cyr (2012) argumentaram que a adoção de sistemas mais proporcionais no Japão e na França, nas décadas de 1990 e 1980, respectivamente, pode ter aumentado a representação de mulheres no primeiro, mas não no segundo. Algo semelhante pode ser dito do Brasil, onde sistemas eleitorais diferentes são usados nas eleições para o Senado e para a Câmara Federal, apesar do número de mulheres eleitas ser pequeno em ambas as casas. Em último caso, portanto, o efeito da magnitude eleitoral é algo a ser investigado em cada caso particular. No restante do artigo, apresentamos os resultados da nossa estratégia empírica para examiná-lo nas câmaras municipais brasileiras.

\section{Desenho de pesquisa}

III.1. Estratégia de identificação

Para estimar o efeito da magnitude eleitoral na representação de mulheres nos legislativos municipais no Brasil, utilizamos regressão descontínua (RD). Este método consiste em comparar unidades que receberam ou não um determinado tratamento que, por sua vez, é função de alguma variável contínua: unidades que ficam pouco acima do ponto de corte nesta variável são comparadas, então, com outras que ficam pouco abaixo do mesmo ponto. Sob certas condições, discutidas a seguir, este método nos permite identificar efeitos causais. Um exemplo ajuda a esclarecer como ele funciona.

Imagine que num país qualquer exista uma regra que estipula que todos os seus municípios com 1.000 ou mais habitantes terão 10 vereadores, enquanto que os com menos de 1.000, apenas 9. Podemos imaginar ainda um município A com exatamente 1.000 habitantes e outro, B, com 999: a população de ambos é quase a mesma, mas, por causa da diferença de um habitante, A ganha um 
${ }^{7}$ Não é objetivo deste artigo fornecer uma introdução mais completa à regressão descontínua. Boas referências podem ser encontradas em Imbens e Lemieux (2008). Outros exemplos de aplicação podem ser encontrados em Brollo e Troiano (2015) e Cepaluni e Mignozzetti (2015).

${ }^{8}$ Como Cepaluni e Mignozzetti (2015) afirmam, esta fórmula se aplica os municípios com menos de um milhão de habitantes. $\mathrm{O}$ número de 47.697 habitantes é o resultado da divisão de um milhão por 21 , número máximo de vereadores que municípios com até este número de habitantes poderia ter. vereador a mais que B. De forma geral, como a probabilidade de ter 10 vereadores aumenta descontinuamente quando municípios passam de 1.000 habitantes, qualquer variável que tenha relação com o número de cadeiras também será afetada. A não ser que municípios consigam determinar o tamanho exato de suas próprias populações, podemos assumir que nos municípios em que o número de habitantes está suficientemente próximo de 1.000, a atribuição de uma cadeira a mais será definida como que por um lançamento de moeda em outras palavras, por meio de um experimento local. É exatamente este pressuposto que nos assegura que o efeito de um tratamento pode ser estimado com RD (Imbens \& Lemieux 2008). ${ }^{7}$

Em 2004 e 2008, um critério populacional semelhante foi instituído nas eleições municipais no Brasil. Pouco antes das eleições de 2004, motivado principalmente pelo caso do município de Mira Estrela, em São Paulo, onde os vereadores decidiram aumentar o número de cadeiras na Câmara de 9 para 11, o Tribunal Superior Eleitoral (TSE) determinou, através da Resolução 21.702/2004, que o número de vereadores de cada município a partir de então seria fixado de acordo com o tamanho de suas populações: partindo de um mínimo de 9 vereadores, para cada 47.619 habitantes deveria haver um vereador, até um máximo de 21. Por exemplo, municípios com menos de 47.619 habitantes teriam 9 cadeiras, o mínimo; municípios com mais, até 95.238 habitantes, teriam no mínimo 10 cadeiras $^{8}$. Para calcular o número de vereadores que cada município teria direito após a resolução, as estimativas populacionais do IBGE do ano anterior às eleições (2003 e 2007, no caso) foram usadas (Corbi, Papaioannou \& Surico 2014; Cepaluni \& Mignozzetti 2015).

Como antes desta data o número de vereadores em cada município era estipulado apenas pela Constituição Federal de forma ampla (segundo o art. 29, municípios com até um milhão de habitantes poderiam ter entre 9 e 21 vereadores), o efeito prático desta resolução foi o de acabar com distorções: por exemplo, em 2000, tanto Alegrete (RS) quanto Uberlândia (MG) tinham 21 vereadores, embora a população de ambos os municípios fosse de 84.516 e de 487.222, respectivamente (Corbi, Papaioannou \& Surico 2014). Inicialmente, a resolução do TSE seria provisória, devendo aguardar deliberação pelo Congresso. Como a questão só foi tratada em 2009, quando foi regulamentada por meio da Emenda Constitucional n. 58, o TSE aplicou a mesma resolução novamente em 2008. Independentemente disso, esta regra nos oferece a oportunidade de examinar os efeitos causais do número de vereadores sobre a representação política de mulheres.

Para o desenho proposto, consideramos apenas a primeira faixa (municípios com populações entre 0 e 95.238 habitantes), onde justamente uma cadeira adicional pode ter mais impacto, além de ser onde mais de $95 \%$ dos municípios brasileiros se encontrava em 2008. Nosso objetivo, assim, é comparar municípios com populações bastante semelhantes que, por diferenças mínimas, acabaram recebendo ou não uma vaga adicional nas câmaras municipais.

Sendo $\mathrm{X}_{\mathrm{ijt}}$ o número de habitantes de um município, podemos definir uma variável $\mathrm{W}_{\mathrm{ijt}}$ que mostra o tratamento nesta faixa. $\mathrm{O}$ valor $\mathrm{W}_{\mathrm{ijt}}=1$ indica $\mathrm{um}$ município com 47.619 ou mais habitantes e que, portanto, recebeu uma cadeira a mais. Por sua vez, o valor $\mathrm{W}_{\mathrm{ijt}}=0$ indica um município que não recebeu uma cadeira adicional. Seja $\mathrm{Y}_{\mathrm{ijt}}(0)$ e $\mathrm{Y}_{\mathrm{ijt}}(1)$ a variável de interesse (número de mulheres eleitas, por exemplo) num município $i$, num estado $j$ e num tempo $t$, caso o município tenha $\mathrm{W}_{\mathrm{ijt}}=1$ ou $\mathrm{W}_{\mathrm{ijt}}=0$, queremos estimar $\mathrm{Y}_{\mathrm{ijt}}(1)-\mathrm{Y}_{\mathrm{ijt}}(0)$.

Como dito anteriormente, quanto mais próximo for $\mathrm{X}_{\mathrm{ijt}}$ do patamar de corte estabelecido pelo TSE, mais podemos assegurar que a atribuição do tratamento foi distribuída como que aleatoriamente entre os municípios, o que nos permite estimar o efeito causal daquele quando o valor de $\mathrm{X}_{\mathrm{ijt}}$ converge em 47.619: 


$$
E T M L=E\left[Y_{i j t}(1) \mid X_{i j t}=47619\right]-E\left[Y_{i j t}(0) \mid X_{i j t}=47619\right]
$$

onde ETML é o efeito do tratamento médio local, $\mathrm{Y}_{\mathrm{ijt}}$ é variável dependente e $\mathrm{X}_{\mathrm{ijt}}$ é o tamanho da população. A ideia central aqui é que, caso o tratamento cause algum efeito, veremos uma descontinuidade na variável de interesse condicional ao tamanho da população: quando um município passa de 47.618 habitantes para 47.619, por exemplo, a probabilidade de o município receber uma cadeira a mais aumenta descontinuamente de 0 a 100 e, deste modo, qualquer efeito do tratamento seguirá o mesmo padrão. O Gráfico 2 ilustra isto visualmente. Como é possível verificar, quando o número de habitantes dos municípios passa pelo patamar, representado pela linha vertical pontilhada, estes recebem uma cadeira a mais e, justamente por isso, qualquer efeito causado por esta atribuição (como esperamos no caso da representação de mulheres) também mudará descontinuamente a partir dali9. A distância vertical entre as duas curvas, isto é, o salto nas linhas sólidas, quando o número de habitantes é igual a 47.619, é o que queremos estimar. Quando mais visível for a distância entre as duas curvas neste ponto, maior o efeito causal.

\section{III.2. Dados}

\footnotetext{
${ }^{9}$ Este desenho, chamado de sharp, aplica-se aos casos em que a atribuição do tratamento é uma função determinística da forcing variable. Nos casos onde o tratamento é uma função probabilística (a unidade fica habilitada a receber o tratamento), a estratégia empírica seria diferente (Imbens \& Lemieux 2008).
}

Para a análise, reunimos dados de diferentes fontes. Do TSE, foram obtidas informações sobre o número de vagas em disputa para as eleições proporcionais de 2004 e 2008 nos municípios, bem como sobre os candidatos que as disputaram e os resultados de cada um. Dados demográficos municipais foram compilados a partir do Instituto Brasileiro de Geografia e Estatística (IBGE). Em particular, o número de habitantes de cada município é fundamental para a análise, já que foi a partir das estimativas populacionais do IBGE de 2003 e 2007 que o TSE determinou alocação do número de vereadores nas eleições de 2004 e 2008, respectivamente (Corbi, Papaioannou \& Surico 2014; Cepaluni \& Mignozzetti 2015). Especificamente, centramos a variável população ao redor da descontinuidade para que 0 indicasse 47.619 habitantes; números menores de habitantes, deste modo, ficam negativos (indicando quantos habitantes faltam para que um município tenha 47.619). Com estes dados, criamos uma

Gráfico 2 - Exemplo de como a regressão descontínua (RD) identifica um efeito causal

Atribuição do tratamento

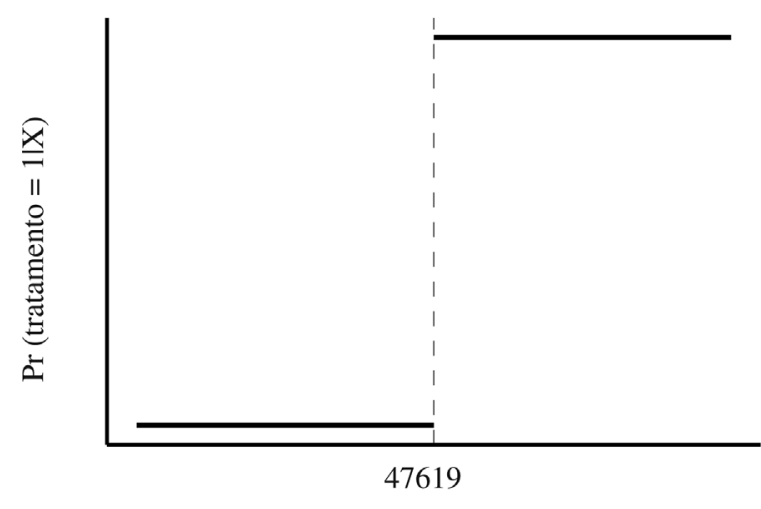

Habitantes
Efeito do tratamento

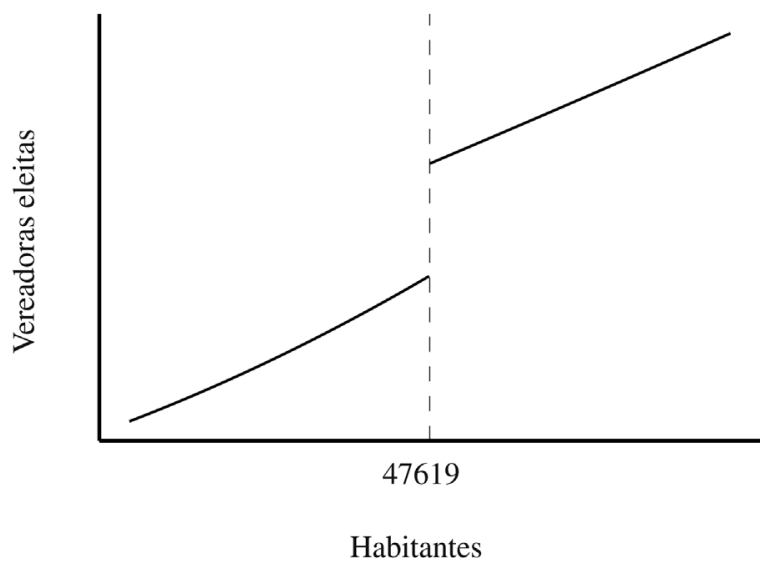

Fonte: Os autores, a partir das fontes descritas no Apêndice.

Nota: Os painéis exemplificam como um efeito causal é identificado pela regressão descontínua. As linhas sólidas indicam a variável dependente $\mathrm{Y}_{\mathrm{ijt}}$ (probabilidade de ter um vereador a mais e o número hipotético de mulheres eleitas, respectivamente). $\mathrm{O}$ eixo $\mathrm{X}_{\mathrm{ijt}}$ indica o número de habitantes dos municípios na amostra e, as linhas verticais tracejadas, a descontinuidade na atribuição de cadeiras quando este é igual a 47.619. 
base contendo 10.842 municípios únicos com menos de 95.238 habitantes, isto é, todos aqueles cujo número de cadeiras alocadas pela regra do TSE foi de 9 ou 10. A descrição completa das fontes e estatísticas descritivas das principais variáveis estão no Apêndice 1.

As principais variáveis dependentes são três. A primeira é o número de mulheres eleitas em cada município, calculadas a partir dos dados do TSE. A segunda é uma binária, onde 1 indica que ao menos uma mulher se elegeu vereadora; como mostramos na seção anterior, parte considerável dos municípios brasileiros não elege sequer uma mulher e, por isso, romper com essa barreira é algo de impacto substantivo. A terceira variável é a proporção de mulheres eleitas em relação ao total de eleitos, o que nos indica, no cômputo geral, qual sexo se beneficiou mais da cadeira a mais - já que é possível, por exemplo, que tanto a representação de homens quanto de mulheres aumente com uma cadeira adicional. Complementarmente, também empregamos outras variáveis, descritas na análise seguinte, para examinar outros efeitos da magnitude eleitoral, testar possíveis mecanismos explicativos e averiguar se o desenho capta efeitos pré-tratamento, isto é, de variáveis que sabemos não serem influenciadas pelo número de vereadores. Caso não encontremos efeitos, isso nos dará maior confiança na validade do desenho utilizado (Imbens \& Lemieux 2008). Outros testes de validação são reportados no Apêndice 1.

III.3. Modelos

Para estimar o efeito causal do aumento de uma unidade na magnitude eleitoral nas câmaras, estimamos modelos MQO com a seguinte forma (Imbens \& Lemieux 2008):

$$
\begin{aligned}
& Y_{i j t}=\alpha+\beta W_{i j t}+\gamma_{1} X_{i j t}+\delta_{1} W_{i j t} X_{i j t}+ \\
& \ldots+\gamma_{2} X_{i j t}^{2}+\delta_{2} W_{i j t} X_{i j t}^{2}+e_{i j t}
\end{aligned}
$$

onde $\mathrm{Y}_{\mathrm{ijt}}$ é a variável dependente; $\mathrm{X}_{\mathrm{ijt}}$ é a população dos municípios, centrada na descontinuidade; $\mathrm{W}_{\mathrm{ijt}}$ é um indicador binário do tratamento ( 1 = uma cadeira adicional, $0=$ sem cadeira adicional); e $\beta$ retorna o efeito causal do tratamento, isto é, a diferença nas duas curvas estimadas no ponto 0 . Este tipo de modelo nos permite estimar aquelas curvas vistas no exemplo ilustrativo e, deste modo, mensurar a distância, ou o salto, nas variáveis dependentes ao redor da descontinuidade. Caso o tratamento não cause efeito algum nas unidades tratadas, as duas curvas se tocam ao redor da descontinuidade e, consequentemente, o coeficiente do estimador RD será próximo ou igual a 0.

Um segundo detalhe da especificação é a janela (bandwidth) ao redor da descontinuidade. Como estamos interessados nos casos mais próximos possíveis de 0 , poderíamos restringir esta janela ao máximo, selecionando apenas municípios com populações muito próximas de 47.697. Fazendo isto, contudo, reduziríamos consideravelmente o tamanho da amostra. O ideal, portanto, é selecionar uma janela que equilibre proximidade da descontinuidade (para evitar vieses no estimador) e número de observações (para aumentar o poder estatístico) (Imbens \& Lemieux 2008). O algoritmo de Imbens e Kalyanaraman (2011) cumpre exatamente esta função. De qualquer modo, reportamos os principais resultados com janelas diferentes para testar a sensibilidade deles (no Apêndice 1 também reportamos uma série de testes de validação).

\section{Resultados e discussão}

Como pode ser visto no Gráfico 3, os resultados mostram que uma cadeira a mais aumenta substantiva e significativamente o número de vereadoras eleitas. 
Especificamente, os painéis à esquerda mostram o salto nas variáveis dependentes ao redor da descontinuidade, isto é, quando o número de cadeiras passa de 9 para 10, acompanhados de duas curvas, estimadas em cada lado. Como pode ser visto, a distância entre as duas curvas é visível, indicando que o efeito da magnitude eleitoral existe e é considerável: o número de mulheres eleitas aumenta cerca de 0,45 ; por sua vez, a probabilidade de um município com uma cadeira a mais eleger ao menos uma mulher é de cerca de 20 pontos percentuais maior. Já os painéis à direita mostram que estes resultados não mudam quando alteramos o número de observações ao redor da descontinuidade, isto é, eles não são sensíveis à janela utilizada; no eixo X, estão as janelas utilizadas para estimar o efeito causal e, a área em cinza, neste caso, indica o intervalo de confiança de $95 \%$ destas estimativas.

A Tabela 1 complementa esta análise, mostrando que o uso de outras especificações, com polinômios maiores (i.e., número de habitantes ao quadrado, ao cubo, etc., interagido com a dummy que indica o tratamento), também não altera os resultados. Acompanhados do estimador RD, que indica o efeito causal médio do tratamento, as linhas da tabela também indicam os errospadrão das estimativas, o número de observações e a janela utilizadas. Enfim, embora todas estas estimativas pareçam pequenas, o efeito delas é relativamente grande quando considerado que a boa parte destes municípios normalmente elege apenas 1 ou nenhuma mulher, além de que ele se deve ao acréscimo de apenas uma cadeira. De forma mais geral, conforme a literatura sustenta, o aumento no número de cadeiras amplia a representação de mulheres nas câmaras municipais, ao menos naquelas em que o efeito pode ser identificado.

Por si só, estes resultados ainda nos dizem pouco. Com uma cadeira adicional em disputa, pode ser que tanto homens quanto mulheres se beneficiem, na média. Para examinar quem ganha mais relativamente, estimamos outros modelos com a proporção de mulheres eleitas em relação ao total de eleitos como variável dependente. Com isso, podemos saber quem ganhou mais: caso a proporção de homens eleitos com uma cadeira adicional seja maior,

Tabela 1 - Estimativas do efeito de uma cadeira adicional nas câmaras municipais na representação de mulheres

\begin{tabular}{|c|c|c|c|c|c|}
\hline & Polinômio & 1 & 2 & 3 & 4 \\
\hline \multirow[t]{4}{*}{ Número de mulheres eleitas } & Estimador & $0.28 *$ & $0.41 *$ & $0.45^{*}$ & 0.45 \\
\hline & Erro-padrão & $(0.11)$ & $(0.15)$ & $(0.19)$ & $(0.26)$ \\
\hline & Janela & 33446.54 & 35926.59 & 45702.17 & 39938.7 \\
\hline & $\mathrm{N}$ & 3.670 & 4.460 & 5.191 & 5.149 \\
\hline \multirow{4}{*}{$\begin{array}{l}\text { Probabilidade de eleger ao } \\
\text { menos uma mulher }\end{array}$} & Estimador & $0.14 *$ & $0.19 *$ & $0.2^{*}$ & 0.23 \\
\hline & Erro-padrão & $(0.05)$ & $(0.08)$ & $(0.1)$ & $(0.12)$ \\
\hline & Janela & 31588.38 & 31187.67 & 35531.95 & 39310.26 \\
\hline & $\mathrm{N}$ & 3.184 & 3.101 & 4.330 & 5.146 \\
\hline \multirow[t]{4}{*}{ Proporção de mulheres eleitas } & Estimador & 0.02 & $0.03 *$ & 0.03 & 0.04 \\
\hline & Erro-padrão & $(0.01)$ & $(0.02)$ & $(0.02)$ & $(0.03)$ \\
\hline & Janela & 31851.7 & 36447.38 & 44055.31 & 40311.67 \\
\hline & $\mathrm{N}$ & 3.252 & 4.627 & 5.173 & 5.152 \\
\hline
\end{tabular}

Fonte: Os autores, a partir das fontes descritas no Apêndice.

* p-valor < 0.05. Erros-padrão robustos entre parêntesis.

Notas: As janelas (número de habitantes a mais ou a menos da descontinuidade) foram selecionadas através do método proposto por Imbens e Kalyanaraman (2011). Os modelos estão ordenados segundo a ordem dos polinômios usados para estimá-los. 
Gráfico 3 - Efeito do aumento de uma cadeira nas câmaras municipais no número de vereadoras eleitas, na probabilidade de eleger ao menos uma vereadora e na proporção de mulheres eleitas (eleições de 2004 e 2008)
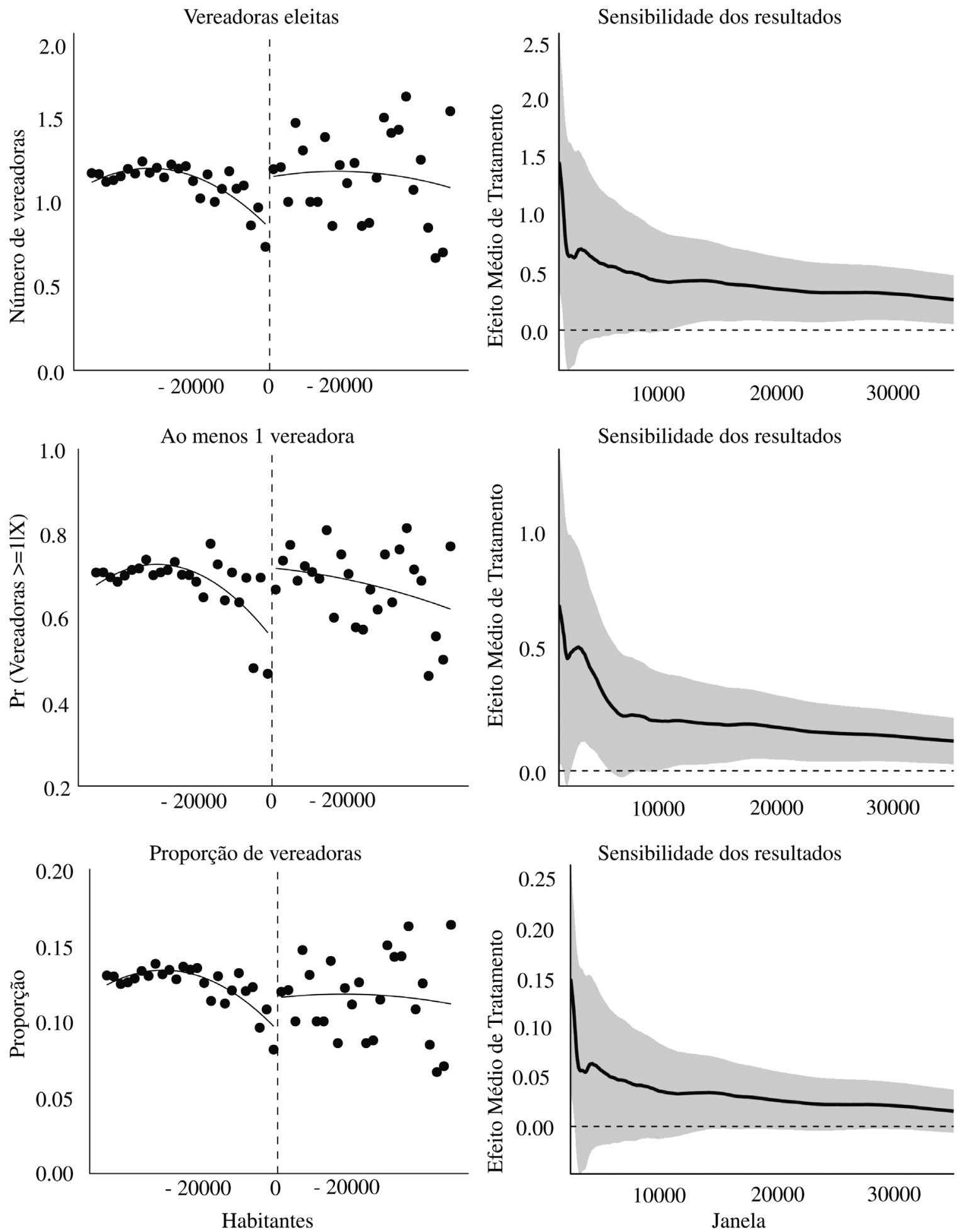

Fonte: Os autores, a partir das fontes descritas no Apêndice.

Notas: Os painéis da esquerda mostram o salto na variável dependente quando o número de cadeiras nas câmaras aumenta em uma unidade; o eixo X indica o número de habitantes dos municípios, centrado na descontinuidade (47.619, indicado pela linha vertical tracejada); as linhas sólidas indicam as curvas estimadas com polinômio de ordem 2 nos dois lados da descontinuidade; os pontos em preto são a média na variável independente em intervalos de 1.887 habitantes - este é um procedimento recomendado pela literatura para melhor visualizar padrões em regressões descontínuas. Os painéis à direita mostram os mesmos efeitos do tratamento em diferentes janelas ao redor da descontinuidade (quantas observações ao redor de 0 são incluídas no modelo); a linha horizontal tracejada identifica onde o efeito é 0 . 
aquele aumento no número de mulheres eleitas ainda assim significaria que mulheres foram menos beneficiadas com a mudança. Os resultados destes modelos, reportados nos dois últimos painéis do Gráfico 3 e na última linha da Tabela 1, mostram que este não é o caso: a proporção de mulheres eleitas vereadoras aumentou cerca de 0,03 nos municípios sob tratamento - apesar deste efeito não ser significativo em algumas especificações, mas chegar a quase 0,15 ao usarmos uma janela menor. Na pior das hipóteses, em suma, mulheres se beneficiaram do aumento no número de cadeiras tanto quanto homens e, na melhor delas, se beneficiaram muito mais. Independentemente disto, contudo, o resultado geral se mantém: o aumento absoluto no número de vereadoras é substantivo onde uma cadeira a mais estava disponível.

\section{IV.1. O que explica o aumento no número vereadoras?}

Até aqui, investigamos o efeito causal que uma cadeira a mais para vereador tem sobre a representação de mulheres. Particularmente, os resultados são claros ao mostrar que este efeito é positivo: o número de mulheres eleitas aumenta quase $40 \%$, apesar de partir de um patamar baixo, e a probabilidade de um município com uma cadeira a mais eleger ao menos uma mulher aumenta cerca de 20 pontos percentuais. Neste espaço, procuramos agora compreender quais são os mecanismos causais que explicam este efeito. Como apresentamos anteriormente, três mecanismos principais são mencionados na literatura sobre o tema para dar conta disso: (1) o de que a alocação de cadeiras seria mais proporcional entre candidatos em sistemas com maior magnitude eleitoral; (2) o de que maior magnitude incentivaria mais candidaturas de mulheres; (3) que maior magnitude incentivaria os eleitores a votar de forma não estratégica, o que poderia favorecer candidatas mulheres.

Para examinar estes possíveis mecanismos causais ligando número de cadeiras e representação de mulheres, examinamos, na Tabela 2, o efeito da magnitude sobre algumas variáveis intermediárias. A primeira variável analisada é o número de candidatos concorrendo, já que, com mais cadeiras à disposição, esperamos que tanto o número total de candidatos quanto o número de candidatas mulheres, como sustenta a literatura, aumentem. Utilizamos duas operacionalizações desta variável: número total de candidatos e o Número de Candidatos Efetivos (NCE), calculado como

$$
N C E=\frac{1}{\sum_{i=1}^{n} c_{i j t}^{2}}
$$

onde $c$ é a percentagem de votos de cada candidato $i$ num determinado município $j$ numa dada eleição em $t$. Calculamos estas variáveis para candidatos homens e para candidatas mulheres.

Os resultados na Tabela 2 mostram que, de forma geral, uma cadeira a mais causa um aumento no Número de Candidatos Efetivos, de acordo com a operacionalização da variável descrita no início desta seção, tanto no geral, como seria de se esperar, quanto de candidatos homens (cerca de 7 candidatos efetivos e 9 candidatos a mais onde havia uma cadeira adicional); por outro lado, o número de candidaturas de mulheres não aumenta, isto é, ele não é significativamente diferente entre municípios com 9 e 10 cadeiras. Uma possível explicação para isso é que, por causa da cota que estabelece um mínimo de $30 \%$ de mulheres nas listas partidárias, os partidos podem não ter incentivos para recrutar mais mulheres nas listas para além deste valor ${ }^{10}$. A despeito disso, estes resultados mostram que um aumento no número de candidaturas de mulheres não parece ser o que provocou um aumento no número de vereadoras eleitas nas câmaras, ainda que este mecanismo possa atuar em outros contextos. 
Tabela 2 - Estimativas do efeito de uma cadeira adicional nas câmaras municipais em variáveis intermediárias

\begin{tabular}{lccc}
\hline Variável & Estimador & IC (95\%) & N \\
\hline $\mathrm{N}^{\circ}$ Candidatos Efetivos (todos) & $5,46^{*}$ & {$[1.45,9.47]$} & 10.347 \\
$\mathrm{~N}^{\circ}$ Candidatos Efetivos (mulheres) & $-133,52$ & {$[-499.15,232.11]$} & 568 \\
$\mathrm{~N}^{\circ}$ Candidatos Efetivos (homens) & $6,97^{*}$ & {$[1.89,12.04]$} & 8.402 \\
$\mathrm{~N}^{\circ}$ Candidatas mulheres & 0,79 & {$[-2.28,3.85]$} & 5.628 \\
$\mathrm{~N}^{\circ}$ Candidatos homens & $8,91^{*}$ & {$[2.52,15.29]$} & 7.624 \\
Votos em candidatas mulheres & 104,03 & {$[-292.09,500.14]$} & 4.799 \\
Votos em candidatos homens & 224,81 & {$[-772.7,1222.33]$} & 3.587 \\
Votos em candidatas mulheres (média) & 4,46 & {$[-23.53,32.45]$} & 10.293 \\
Votos em candidatos homens (média) & $-29,18$ & {$[-65.61,7.24]$} & 8.900 \\
Votos em candidatas mulheres (mediana) & $-0,75$ & {$[-25.14,23.63]$} & 8.760 \\
Votos em candidatos homens (mediana) & $-28,02$ & {$[-60.31,4.27]$} & 10.347 \\
$\mathrm{~N}^{\circ}$ Vereadoras eleitas (2004) & $0,49 *$ & {$[0.07,0.91]$} & 2.729 \\
$\mathrm{~N}^{\circ}$ Vereadoras eleitas (2008) & 0,32 & {$[-0.08,0.72]$} & 3.448 \\
$\mathrm{~N}^{\circ}$ Mulheres no eleitorado & $-312,55$ & {$[-1446.6,779.22]$} & 3.105 \\
$\mathrm{~N}^{\circ}$ Eleitores com ensino superior & $-333,69$ & 4.011 \\
\hline
\end{tabular}

Fonte: Os autores, a partir das fontes descritas no Apêndice.

$*$ p-valor $<0.05$.

Notas: Os coeficientes foram estimados com duas regressões MQO, uma em cada lado da descontinuidade, com polinômios de ordem 2. Os intervalos de confiança, entre colchetes, foram calculados a partir de erros-padrão robustos. As janelas usadas foram selecionadas através do método proposto por Imbens e Kalyanaraman (2011).

${ }^{10}$ Como o número de cadeiras é pequeno neste contexto, mesmo que os partidos cumprissem a cota de $30 \%$ - o que não acontece em vários locais, como visto anteriormente - o número de candidatas mulheres não aumentaria substantivamente.
$\mathrm{O}$ aumento de candidaturas de homens, aliado à manutenção do número de candidaturas de mulheres, por outro lado, parece ser a chave da explicação, como sugerem os demais resultados a seguir.

Para investigar os mecanismos 1 e 3 , comparamos as votações que candidatas mulheres receberam nos dois grupos de municípios. Caso mulheres tenham votações semelhantes em locais com 9 ou 10 cadeiras, temos maior suporte para a hipótese de que foi a alocação mais proporcional, e não o comportamento dos eleitores, que causou aquele aumento na representação; por outro lado, mudanças nos padrões de votações poderiam indicar que o mecanismo causal atuou pelo lado da demanda eleitoral, algo de acordo com o que propõe o argumento 3. Para garantir que os resultados não dependem da operacionalização adotada, novamente utilizamos mais de uma variável para mensurar os padrões de votação. A primeira é o total de votos que os candidatos receberam num município e numa eleição determinada; a segunda e a terceira, a média e a mediana de votos que os candidatos receberam, respectivamente; por último, a diferença entre a votação média de candidatos e a votação média de candidatas.

Os resultados destes modelos mostram que, de novo, as expectativas da literatura não são corroboradas. Mulheres não recebem mais votos onde havia uma cadeira a mais, e nem a votação média delas aumenta - as estimativas são próximas de zero e não atingem significância. Em conjunto com os resultados anteriores, portanto, temos evidências de que nem o número de candidaturas de mulheres e nem o apoio do eleitorado a elas aumentou. Curiosamente, algum efeito é encontrado no campo dos candidatos homens: com uma cadeira a mais, o desempenho eleitoral médio deles piora em cerca de 30 votos, embora o efeito também não atinja significância. $\mathrm{O}$ desempenho de homens também parece piorar no geral e na mediana, o que mostra que o efeito se mantém em outras 
operacionalizações. Comparando o desempenho médio e mediano de candidatos homens e mulheres, entretanto, encontramos alguns efeitos significativos, como mostra o Gráfico 4. No geral, ele mostra que a diferença de desempenho mediano dos candidatos homens e das candidatas mulheres cai cerca de 25 votos - o que é algo considerável, dado que o quociente eleitoral nestes municípios é baixo.

Enfim, estas evidências indicam que o mecanismo atuando aqui não foi nenhum dos sugeridos pela literatura. O que parece ter ocorrido, na verdade, foi um problema de coordenação entre candidatos homens: com uma cadeira adicional, estes tiveram maiores incentivos para concorrer (o número de votos relativos necessários para se eleger diminuiu), embora o número de candidatas e a votação delas tenham se mantido praticamente constante; deste modo, o campo de candidatos homens acabou fragmentando o eleitorado, e isto, de forma

Gráfico 4 - Efeito do aumento de uma cadeira nas câmaras municipais na diferença média e mediana de votos entre candidatos homens e mulheres (eleições de 2004 e 2008)
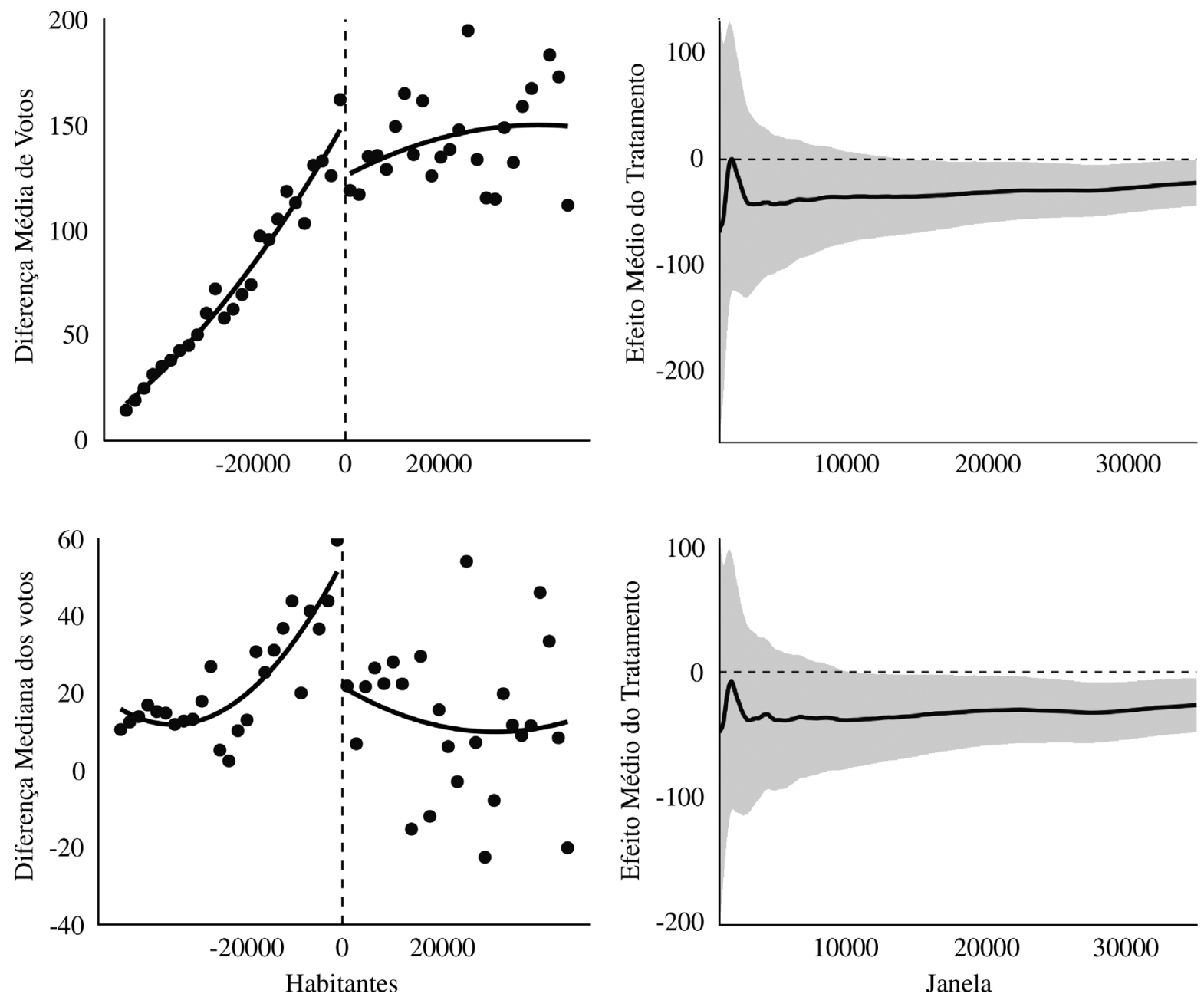

Fonte: Os autores, a partir das fontes descritas no Apêndice.

Notas: Os painéis da esquerda mostram o salto na variável dependente quando o número de cadeiras nas câmaras aumenta em uma unidade; o eixo X indica o número de habitantes dos municípios, centrado na descontinuidade (47.619, indicado pela linha vertical tracejada); as linhas sólidas indicam as curvas estimadas com polinômio de ordem 2 nos dois lados da descontinuidade; os pontos em preto são a média na variável independente em intervalos de 1.887 habitantes - este é um procedimento recomendado pela literatura para melhor visualizar padrões em regressões descontínuas. Os painéis à direita mostram os mesmos efeitos do tratamento em diferentes janelas ao redor da descontinuidade (quantas observações ao redor de 0 são incluídas no modelo); a linha horizontal tracejada identifica o local onde o efeito é 0. 
${ }^{11}$ Para o nosso conhecimento, a única menção na literatura a um possível efeito de fragmentação na votação de candidatos de diferentes gêneros é feita brevemente por Schmidt (2009, p.194), mas no sentido contrário do que documentamos aqui, isto é, sugerindo que maior magnitude levaria a uma fragmentação na votação de candidatas mulheres.
12 Testamos também os efeitos de uma cadeira a mais nos municípios da segunda faixa definida pelo TSE, com 10 e 11 cadeiras, e encontramos efeitos menores que os mostrados anteriormente. Como o número de cadeiras nestes municípios é maior, o agregada, resultou num pior desempenho de todos eles. A consequência final são mais mulheres eleitas, mesmo que nada tenha mudado na oferta e na demanda eleitoral de candidatas ${ }^{11}$.

Este resultado não antecipado assemelha-se a um típico dilema dos prisioneiros. Primeiro, porque o custo de competir vis-à-vis os benefícios de se eleger eram maiores dos que o de não concorrer (ao menos para candidatos homens); segundo, porque isto só se manteria caso um número suficiente de candidatos homens não decidisse se candidatar (optando pela estratégia de cooperação). De forma geral, como a estratégia ótima era concorrer, muitos homens concorreram e acabaram com um benefício final menor do que teriam obtido caso tivessem se coordenado em torno de apenas algumas candidaturas, que poderiam, assim, ter obtido mais votos. Outra evidência que corrobora esta explicação é o fato de que o número de mulheres eleitas vereadoras foi maior em 2004 do que em 2008 (Tabela 2), o que sugere que, nestas últimas eleições, a coordenação no lançamento de candidaturas de homens pode ter sido mais eficiente, o que diminuiu a fragmentação em suas votações.

A principal questão remanescente é o porquê de as mulheres não terem sido afetadas pela magnitude eleitoral de forma direta. Como argumentamos anteriormente, o número de candidatas mulheres não aumentou com uma cadeira a mais, o que pode indicar que os partidos não estão dispostos a incluir mais candidatas para além do que a Lei de Cotas já estipula, 30\%. De todo o modo, também pode ser o caso de que mulheres não são incentivadas a concorrer com uma cadeira a mais, especialmente se elas tiverem outras considerações em mente, como suporte da família, trabalho ou disponibilidade de tempo livre. Já no lado do eleitorado, o suposto comportamento estratégico, que poderia tirar votos de mulheres, não encontra suporte nos dados. Ao contrário, o número de eleitores dispostos a votar em candidatas parece ser o mesmo nos dois grupos de municípios. Se isto se alteraria em eleições para outros cargos, ou com aumentos maiores no número de cadeiras, contudo, é uma questão em aberto.

Nos últimos modelos reportados na Tabela 2, analisamos o efeito da magnitude sobre variáveis pré-tratamento, isto é, variáveis que sabemos de antemão não terem relação com o número de cadeiras - para corroborar a validade do desenho (Imbens \& Lemieux 2008). Como esperado, as estimativas sobre a proporção de mulheres no eleitorado e o número de eleitores com Ensino Superior não são significativamente diferentes nos dois grupos de municípios analisados, o que nos dá maiores garantias de que os demais resultados são consistentes. O resultado de outros testes de validação, reportados no Apêndice 1 , também dão suporte ao nosso desenho.

Antes de concluirmos, uma nota sobre a validade externa dos resultados reportados acima é necessária. Como é usual em pesquisas experimentais ou quase-experimentais, o ganho em validade interna, que nos permite fazer inferências causais, às vezes vem acompanhado de perda de validade externa. Na regressão descontínua, em particular, isto acontece porque os efeitos estimados só valem para as observações muito próximas da descontinuidade, justamente onde a atribuição do tratamento é exógena aos efeitos examinados. Dito de outra forma, não é possível estimar o efeito de uma cadeira adicional em municípios com, digamos, 5 ou 70 mil habitantes. Embora seja razoável supor que o efeito ainda seja positivo nestes $\operatorname{casos}^{12}$, a principal contribuição deste artigo é outra.

Por meio do exame do efeito causal do número de cadeiras, procuramos oferecer suporte mais consistente para o argumento da literatura sobre o tema, qual seja, o de que maior magnitude eleitoral poderia ampliar a representação de minorias políticas. Conforme estudos mais recentes já haviam sustentado (Roberts, Seawright \& Cyr 2012; Salmond 2006; Schmidt 2009), frequentemente o 
retorno marginal diminui - o que mostra que uma cadeira a adicional tem maior importância justamente nos municípios menores. efeito do sistema eleitoral na representação de mulheres é sobrestimado, isto é, ele é considerado muito maior do que de fato é. Os problemas que levam a estes achados são basicamente os que procuramos contornar aqui: omissão de variáveis importantes, erros de mensuração e ausência de bons contrafactuais. Além disso, estes estudos também mostram que o efeito de um tipo de sistema eleitoral pode ser heterogêneo: não podemos esperar de antemão que um sistema proporcional produzirá automaticamente a mesma representação de mulheres em dois contextos diferentes. Ao analisarmos especificamente o caso do Brasil, assim, nossos resultados contribuem com esta crescente literatura, que usa novos métodos para avaliar os efeitos causais do sistema eleitoral sobre a representação de mulheres, num local diferente daqueles tradicionalmente estudados, normalmente países europeus.

\section{Conclusões}

Mulheres não estão em pé de igualdade com homens quando o assunto é eleições. Nos municípios brasileiros, mulheres ocupam apenas uma fração dos cargos eletivos, a despeito das iniciativas tomadas visando reduzir esta desigualdade nos últimos anos. No entanto, como proposto pela literatura, diversos aspectos institucionais podem impactar diretamente o número de mulheres eleitas, seja incentivando mais mulheres a competir, seja garantindo condições mais igualitárias nas disputas.

Como procuramos mostrar, a magnitude eleitoral, isto é, o número de cadeiras disponíveis por distrito, é um aspecto que pode aumentar o número de mulheres eleitas. Nossos resultados, estimados por meio de regressão descontínua, mostram que uma cadeira a mais causou um aumento de cerca de $40 \%$ no número de mulheres eleitas nas câmaras municipais analisadas, em 2004 e 2008, e aumentou a probabilidade de ao menos uma mulher ser eleita em cerca de 20 pontos percentuais. Além disso, esse incremento não se deu apenas em termos absolutos: a proporção de mulheres eleitas também aumentou significativamente, indicando que candidatas mulheres se beneficiaram tanto ou mais que candidatos homens da cadeira adicional. Maior magnitude eleitoral, portanto, pode realmente reduzir a desigualdade na representação de mulheres nos municípios.

As explicações da literatura para dar conta deste fenômeno, por outro lado, não encontraram suporte nos nossos dados. Uma cadeira de vereador a mais não incentivou mais candidaturas de mulheres, tampouco mais eleitores a votar nelas; e, ainda que a distribuição mais proporcional de vagas possa ter desempenhado algum papel naquele efeito, o que parece explicar o maior número de mulheres eleitas onde havia uma cadeira a mais foi outra coisa: a fragmentação da votação dos candidatos homens e a manutenção do número de candidatas mulheres. Com o aumento da magnitude, mais homens se candidataram e, assim, houve maior dispersão nos votos que eles receberam, já que a votação dada às candidaturas femininas não se alterou. Como resultado, o desempenho eleitoral médio dos candidatos homens foi pior - e mais mulheres se elegeram.

Este problema de coordenação, que levou mais homens a competir e dividir votos, tem algumas implicações para a literatura. Em primeiro lugar, ele mostra que, embora o efeito da magnitude esteja de acordo com o esperado, o mecanismo causal ligando número de cadeiras e mulheres eleitas nos municípios brasileiros não era sequer previsto pela literatura. Em segundo lugar, por ser provavelmente uma consequência não antecipada do aumento no número de cadeiras, tal estado de coisas vai ao encontro de estudos que afirmam que reformas eleitorais nem sempre são a solução para aumentar a representação de minorias, já que suas consequências muitas vezes não podem ser totalmente antecipadas (Schimidt 2009; Roberts, Seawright \& Cyr 2012). Se por um lado 
${ }^{13}$ A proposta foi aprovada no Senado e encaminhada para a Câmara dos Deputados, onde aguarda apreciação na Comissão de Constituição e Justiça e Cidadania. Disponível em: http://www2.camara.leg.br/pro posicoesWeb/fichadetramitaca o? idProposicao $=1724716$. Acesso em: 25.jan.2016. um aumento de magnitude pode realmente favorecer a entrada política de mulheres, por outro isto traz à tona a importância de se discutir outras mudanças institucionais, que tenham como prioridade a inclusão de minorias políticas e que a garanta no longo-prazo.

Uma das possíveis formas de contornar tal problema é definir como prioritária a inclusão de grupos minoritários na arena representativa, por meio da criação de mecanismos institucionais e extra eleitorais para que tais grupos tenham sucesso e ocupem as cadeiras que pleiteiam. Um exemplo positivo deste esforço, no Brasil, é a PEC 98, de 2015, que propõe não apenas a reserva de vagas nas listas partidárias, mas de cadeiras legislativas ${ }^{13}$. Levando-se em conta que ainda hoje muitos municípios não têm vereadoras, tal incremento poderia assegurar, de fato, a participação feminina nestas arenas decisórias. Por fỉm, cabe ressaltar que além das alterações institucionais, é preciso que sejam realizadas, cada vez mais, capacitações e cursos que forneçam às mulheres subsídios para que, além de entrarem na disputa eleitoral, em municípios ou estados, se tornem competitivas e sejam eleitas. Desta forma, com a inclusão de diferentes grupos na política formal - e aqui cabe mencionar também pessoas negras, indígenas, LGBTs, apenas para citar alguns - a democracia brasileira poderá se tornar mais representativa e garantir, de forma substantiva, o princípio da equidade.

Fernando Meireles (meirelesff@ hotmail.com) é Doutorando em Ciência Política pela Universidade Federal de Minas Gerais (UFMG). Vínculo Institucional: Programa de Pós-graduação em Ciência Política, UFMG, Belo Horizonte, MG, Brasil.

Luciana Vieira Rubim Andrade (alucianandrade@gmail.com) é Doutoranda em Ciência Política pela Universidade Federal de Minas Gerais (UFMG). Vínculo Institucional: Programa de Pós-graduação em Ciência Política, UFMG, Belo Horizonte, MG, Brasil.

\section{Referências}

Araújo, C., 2005. Partidos políticos e gênero. Revista de Sociologia e Política, 24(24), pp.193-215. DOI: 10.1590/S0104-44782005000100013

2009. Gênero e acesso ao poder legislativo no Brasil: as cotas entre as instituições e a cultura. Revista Brasileira de Ciência Política, 2(2), pp.23-59.

Bohn, S., 2010. Mulheres brasileiras na disputa do legislativo municipal. Perspectivas, 35, pp.63-89.

Boix, C., 1999. Setting the Rules of the Game: The Choice of Electoral Systems in Advanced Democracies. American Political Science Review, 93(3), pp.609-624. DOI: 10.2307/2585577

Brollo, F. \& Troiano, U., 2015. What Happens When a Woman Wins an Election? Evidence from Close Races in Brazil. Journal of Development Economics, 122, pp.28-45. DOI: 10.1016/j.jdeveco.2016.04.003

Cepaluni, G. \& Mignozzetti, U., 2016. Politicians Matter: Legislature Size and Welfare with Evidence from Brazil. SSRN Working Paper. DOI: 10.2139/ssrn.2594318

Corbi, R.; Papaioannou, E. \& Surico, P., 2014. Federal Transfer Multipliers. Quasi-Experimental Evidence from Brazil. National Bureau of Economic Research. Disponível em: http://www.nber.org/papers/w20751.rev0.pdf. Acesso em: 19 ago. 2018.

Dowling, C. \& Miller, M., 2015. Can Information Alter Perceptions about Women's Chances of Winning Office? Evidence from a Panel Study. Politics \& Gender, 11(1), pp.55-88. DOI: 10.1017/S1743923X14000555

Engstrom, R., 1987. District Magnitudes and the Election of Women to the Irish Dáil. Electoral Studies, 6(2), pp.123-132. DOI: 10.1016/0261-3794(87)90019-9

Imbens, G. \& Kalyanaraman, K., 2011. Optimal Bandwidth Choice for the Regression Discontinuity Estimator. The Review of Economic Studies, 79(3), pp.933-959. DOI: 10.1093/restud/rdr043

Imbens, G. \& Lemieux, T., 2008. Regression Discontinuity Designs: A Guide to Practice. Journal of Econometrics, 142(2), pp.615-635. DOI: 10.3386/w13039

Massolo, A., 2005. Gobiernos locales y mujeres: nuevos cambios y desafíos en América Latina. Observatório América Latina Genera: Gestion del Conocimiento para la Equidad de Géner. Disponível em: http://www.americalatinagenera.org/elobservatorio. Acesso em: 5 ago. 2017.

Matland, R., 1993. Institutional Variables Affecting Female Representation in National Legislatures: The Case of Norway. The Journal of Politics, 55(3), pp.737-755. DOI: 10.2307/2131998

Matos, M., 2010. Movimento e Teoria Feminista: é possível reconstruir a teoria feminista a partir do Sul global? Revista de Sociologia e Política, 18(36), pp.67-92. DOI: 10.1590/S0104-44782010000200006 
Matos, M. \& Ramalho, I., 2010. Mais mulheres no poder: contribuição à Formação Política das Mulheres. Brasília: Secretaria de Políticas para as Mulheres.

McCrary, J., 2008. Manipulation of the Running Variable in the Regression Discontinuity Design: A Density Test. Journal of Econometrics, 142(2), pp.698-714. DOI: 10.3386/t0334

Miguel, L., 2003. Capital político e carreira eleitoral: algumas variáveis na eleição. Revista de Sociologia e Política, 20(20), pp.115-134. DOI: 10.1590/S0104-44782003000100010

Miguel, L. \& Biroli, F., 2010. Práticas de gênero e carreiras políticas: vertentes explicativas. Estudos Feministas, 18(3), pp.653-679. DOI: 10.1590/S0104-026X2010000300003

Miguel, L. \& Queiroz, C., 2006. Diferenças regionais e o êxito relativo de mulheres em eleições municipais no Brasil. Revista Estudos Feministas, 14(2), pp.363-386. DOI: 10.1590/S0104-026X2006000200003

Norris, P., 2006. The Impact of Electoral Reform on Women's Representation. Acta Política, 41(2), pp.197-213. DOI: 10.1057/palgrave.ap.5500151

Pinto, C., 2003. Uma história do feminismo no Brasil. São Paulo: Fundação Perseu Abramo.

Renwick, A., 2010. The Politics of Electoral Reform: Changing the Rules of Democracy. Cambridge, MA: Cambridge University Press.

Rezende, D., 2015. Qual o lugar reservado às mulheres? Uma análise generificada de comissões legislativas na Argentina, no Brasil e no Uruguai. Tese de Doutorado. Belo Horizonte: Universidade Federal de Minas Gerais.

Rezende, D. \& Assis, M., 2014. Constituinte soberana para reforma política: oportunidades e limites para a ampliação da participação das mulheres no poder. In L.O. Ribas, ed. Constituinte Exclusiva: um outro sistema político é possível. São Paulo: Expressão Popular.

Reynolds, A., 1999. Women in the Legislatures and Executives of the World: Knocking at the Highest Glass Ceiling. World Politics, 51(4), pp.547-572. DOI: 10.1017/S0043887100009254

Roberts, A.; Seawright, J. \& Cyr, J., 2013. Do Electoral Laws Affect Women's Representation? Comparative Political Studies, 46(12), pp.1555-1581. DOI: 10.1177/0010414012463906

Sacchet, T., 2013. Democracia pela Metade: candidaturas e desempenho eleitoral das mulheres. Cadernos ADENAUER, 2(2), pp.85-109.

Sacchet, T. \& Speck, B., 2012. Financiamento eleitoral, representação política e gênero: uma análise das eleições de 2006. Opinião Pública, 18(1), pp.177-197. DOI: 10.1590/S0104-62762012000100009

Salmond, R., 2006. Proportional Representation and Female Parliamentarians. Legislative Studies Quarterly, 31(2), pp.175-204. DOI: 10.3162/036298006X201779

Schmidt, G., 2009. The Election of Women in list PR Systems: Testing the Conventional Wisdom. Electoral Studies, 28(2), pp.190-203. DOI: 10.1016/j.electstud.2008.08.002

Schwindt-Bayer, L., 2010. Political Power and Women's Representation in Latin America. Oxford: Oxford University Press.

Valdini, M., 2013. Electoral Institutions and the Manifestation of Bias: The Effect of the Personal Vote on the Representation of Women. Politics \& Gender, 9(1), pp. 76-92. DOI: 10.1017/S1743923X12000700

Viotti, M., 2006. Declaração e a plataforma de ação da IV Conferência Mundial sobre a mulher: Pequim 1995. In H. Frossard, ed. Instrumentos internacionais de direitos das mulheres. Brasília: Secretaria Especial de Políticas para Mulheres.

Young, I., 2006. Representação política, identidade e minorias. Lua Nova, 67, pp.139-190. DOI: 10.1590/S0102-64452006000200006

\section{Outras fontes}

Brasil está na lanterna da representação feminina no parlamento, 2015. Correio Braziliense, 27 set. Disponível em: http://agenciapatriciagalvao.org.br/politica/brasil-esta-na-lanterna-da-representacao-feminina-no-parlamento/. Acesso em: 5 ago. 2017.

Brasil. Secretaria de Política para as Mulheres, 2008. II Plano Nacional de Política para as Mulheres. Decreto 6.387, de 5 de março de 2008.

2014. Mais Mulheres no Poder - Eu assumo este compromisso. Disponível em http://www.spm.gov.br/sobre/publicacoes/publicacoes/2014/plataforma-mais-mulheres-no-poder-2014.pdf. Acesso em: 5 ago. 2017.

Brasil. Tribunal Superior Eleitoral, 2015. Repositório de dados eleitorais. Disponível em: http://www.tse.jus.br/eleicoes/estatisticas/repositorio-de-dados-eleitorais. Acesso em: 5 ago. 2017.

IPEA 2015. Ipeadata. Disponível em: http://www.ipeadata.gov.br/. Acesso em: 5 ago. 2017. 


\title{
Electoral Magnitude and Women's Political Representation in Brazilian Municipalities
}

\begin{abstract}
It is a commonly known on the literature of women's political representation that a more proportional electoral system can enhance their odds of being elected. In this article, we test this hypothesis using data from more than 10,000 elections in Brazilian municipalities. Exploiting a rule enacted by the Brazilian Tribunal Superior Eleitoral (TSE) for the 2004 and 2008 elections, which created population thresholds to set the numbers of legislators, we use a Regression Discontinuity Design (RDD) to estimate the causal effect of a unit seat increase on the women's representation at city councils. Our results show this effect is substantive: an additional seat leads to a $40 \%$ increase on the number of elected women, and the probability of a least one woman being elected increased by 20 percentage points. However, we do not find empirical support for the main causal mechanisms proposed in the literature. Specifically, we show that one additional seat increases only the number of running male candidates, which fragmented their vote share; as a result, even with the same performance, more women were elected.
\end{abstract}

KEYWORDS: women's political representation; gender studies; electoral magnitude; Brazilian municipalities; local councils.

This is an Open Access article distributed under the terms of the Creative Commons Attribution Non-Commercial License which permits unrestricted non-commercial use, distribution, and reproduction in any medium provided the original work is properly cited. 


\section{Apêndice}

Os dados utilizados foram retirados de duas fontes: Repositório de Dados do Tribunal Superior Eleitoral (TSE) (Brasil 2015) e do Instituto Brasileiro de Geografia e Estatística. Para fundir as duas bases, fizemos matching usando o Código do IBGE e o Código do TSE de cada município, disponíveis no website do Ipeadata (2015). Especificamente, os dados de votação e de informações do TSE vêm separados em duas bases, com arquivos individuais para cada estado; para fundir todos eles, primeiro juntamos todas as bases por estado e, por fim, fizemos matching nas informações de cada candidato pelo Número de Urna de cada um, i, em cada município, j, em cada eleição, t. A operacionalização das variáveis está descrita no texto. Na Tabela $1 \mathrm{~A}$, seguem as estatísticas descritivas delas.

Adicionalmente, verificamos a validade do nosso desenho por meio de alguns testes recomendados na literatura. O primeiro deles é o proposto por McCrary (2008), que testa a hipótese nula de que existe continuidade na densidade da forcing variable (no caso, a população dos municípios na amostra); se, por qualquer razão, os municípios conseguem manipular suas populações para obter uma cadeira a mais ou a menos, teríamos razões para acreditar que a atribuição do tratamento não é aleatória e que, portanto, nossas estimativas estariam enviesadas. O p-valor deste teste é igual a 0.49 , o que reforça a validade do nosso desenho. Os estudos de Corbi, Papaioannou e Surico (2014) e de Cepaluni e Mignozzetti (2015), que usam estratégias de identificação semelhantes, também encontraram resultados parecidos. Por fim, replicamos alguns resultados do artigo utilizando falsas descontinuidades (em vez de 47.619 habitantes, usamos os valores de 10 mil e -10 mil e de 20 mil e - 20 mil). A ideia é que, fora da descontinuidade, não deveríamos encontrar efeitos significativos. Como a Tabela 2A, abaixo, mostra, isto é exatamente o que encontramos. 
Tabela 1A - Estatísticas descritivas das variáveis utilizadas na análise

\begin{tabular}{|c|c|c|c|c|c|}
\hline Variável & $\mathbf{N}$ & Média & Desvio-Padrão & Mínimo & Máximo \\
\hline $\begin{array}{l}\text { População (centrada na } \\
\text { descontinuidade) }\end{array}$ & 10.357 & $-31.947,30$ & $16.395,63$ & -46.815 & 47.534 \\
\hline $\mathrm{N}^{\circ}$ de candidatos & 10.347 & 51,37 & 31,22 & 9 & 415 \\
\hline $\begin{array}{l}\text { Número de Candidatos Efetivos } \\
\text { (NEC) }\end{array}$ & 10.347 & 28,78 & 12,90 & 5,59 & 149,21 \\
\hline NEC mulheres & 10.293 & $6.779,24$ & $421.224,30$ & 13.10 & $41.280 .625,00$ \\
\hline NEC homens & 10.347 & 33,74 & 15,41 & 5,76 & 168,51 \\
\hline $\begin{array}{l}\mathrm{N}^{\circ} \text { Candidatas mulheres } \\
\text { concorrendo }\end{array}$ & 10.348 & 11,14 & 8,34 & 0 & 62 \\
\hline $\begin{array}{l}\mathrm{N}^{\circ} \text { Candidatos homens } \\
\text { concorrendo }\end{array}$ & 10.348 & 40,49 & 21,74 & 7 & 368 \\
\hline $\begin{array}{l}\text { Total de votos das candidatas } \\
\text { mulheres }\end{array}$ & 10.348 & $1.287,07$ & $1.408,12$ & 0 & 13.994 \\
\hline $\begin{array}{l}\text { Total de votos dos candidatos } \\
\text { homens }\end{array}$ & 10.348 & $7.174,61$ & $7.071,58$ & 358 & 50.098 \\
\hline $\begin{array}{l}\text { Média de votos de candidatos } \\
\text { homens }\end{array}$ & 10.347 & 170,52 & 112,24 & 21,90 & $1.294,29$ \\
\hline $\begin{array}{l}\text { Média de votos de candidatas } \\
\text { mulheres }\end{array}$ & 10.293 & 121,85 & 94,32 & 1,00 & $1.311,00$ \\
\hline $\begin{array}{l}\text { Mediana de votos de candidatos } \\
\text { homens }\end{array}$ & 10.347 & 137,47 & 97.03 & 14.50 & $1,296.50$ \\
\hline $\begin{array}{l}\text { Mediana de votos de candidatas } \\
\text { mulheres }\end{array}$ & 10.293 & 90,41 & 87,20 & 1,00 & $1.773,00$ \\
\hline $\begin{array}{l}\text { Diferença média de votos entre } \\
\text { candidatos homens e mulheres }\end{array}$ & 10.293 & 48,64 & 76,93 & $-826,00$ & 857,04 \\
\hline $\begin{array}{l}\text { Diferença mediana de votos } \\
\text { entre candidatos homens e } \\
\text { mulheres }\end{array}$ & 10.293 & 15,45 & 74,26 & $-838,50$ & 859,25 \\
\hline $\mathrm{N}^{\circ}$ Mulheres eleitas & 10.348 & 1,15 & 1,03 & 0 & 7 \\
\hline Proporção de mulheres eleitas & 10.348 & 0,13 & 0,11 & 0,00 & 0,78 \\
\hline $\begin{array}{l}\text { Ao menos uma mulher eleita } \\
\text { (dummy) }\end{array}$ & 10.348 & 0,70 & 0,46 & 0 & 1 \\
\hline
\end{tabular}

Fonte: Os autores, a partir do Repositório de Dados do Tribunal Superior Eleitoral (TSE).

Nota: Estatísticas descritivas das variáveis usadas nas colunas. A unidade de análise da amostra é município-eleição. 
Tabela 2A - Estimativas do efeito de uma cadeira adicional nas câmaras em falsas descontinuidades

\begin{tabular}{lccc}
\hline Variável & Estimador & IC (95\%) & N \\
\hline $\mathrm{N}^{\circ}$ Vereadoras eleitas (desc. 1000) & $-0,18$ & {$[-0.51,0.15]$} & 3.827 \\
$\mathrm{~N}^{\circ}$ Vereadoras eleitas (desc. -1000) & $-0,03$ & {$[-0.24,0.19]$} & 9.220 \\
$\mathrm{~N}^{\circ}$ Vereadoras eleitas (desc. 2000) & $-0,08$ & {$[-0.57,0.41]$} & 1.155 \\
$\mathrm{~N}^{\circ}$ Vereadoras eleitas (desc. -2000) & $-0,09$ & {$[-0.3,0.11]$} & 6.824 \\
$\begin{array}{l}\text { Prob. de eleger ao menos 1 vereadora } \\
\text { (desc. 1000) }\end{array}$ & 0,02 & {$[-0.14,0.18]$} & 2.880 \\
$\begin{array}{l}\text { Prob. de eleger ao menos 1 vereadora } \\
\text { (desc. -1000) }\end{array}$ & $-0,05$ & {$[-0.15,0.05]$} & 10.206 \\
$\begin{array}{l}\text { Prob. de eleger ao menos 1 vereadora } \\
\text { (desc. 2000) }\end{array}$ & $-0,14$ & {$[-0.33,0.05]$} & 1.613 \\
$\begin{array}{l}\text { Prob. de eleger ao menos 1 vereadora } \\
\text { (desc. -2000) }\end{array}$ & 0,01 & {$[-0.09,0.1]$} & 6.614 \\
\hline
\end{tabular}

Fonte: Os autores, a partir do Repositório de Dados do Tribunal Superior Eleitoral (TSE).

$*$ p-valor $<0.05$.

Notas: Os coeficientes foram estimados com duas regressões OLS, uma em cada lado da descontinuidade, com polinômios de ordem 2. Os intervalos de confiança, entre colchetes, foram calculados a partir de erros-padrão robustos. As janelas usadas foram selecionadas através do método proposto por Imbens e Kalyanaraman (2011). 